\title{
Cost-Effectiveness of Closed Incison Negative Pressure Wound Therapy for Reducing Surgical Site Infections
}

\author{
(1) Gaye Çelikcan, ${ }^{1}$ (1) Menekşe Kastamoni, ${ }^{2}$ (1) Ramazan Kahveci² \\ 'Department of Family Medicine, Bursa Uludag University, Bursa, Turkey \\ ${ }^{2}$ Department of Plastic and Reconstructive Surgery, Bursa Uludag University, Bursa, Turkey
}

\section{ABSTRACT}

Objectives: Current preventive measures for the prevention of surgical site infections (SSI) are still not sufficient. We aimed to investigate the cost-effectiveness of negative pressure wound therapy (NPWT) on closed incisions in reducing SSI by reviewing local data or available data and values.

Methods: We suggested a complication cost model for 100 patients, one-fourth of which were presumed as high-risk patients. In high-risk patients, the cost of negative pressure wound therapy (Prevena ${ }^{\top M}$ ) was added to the complication cost. The control group was another hypothetical group of patients, and the SSI cost was also calculated. The cost of negative pressure wound therapy (Prevena ${ }^{\mathrm{TM}}$ ) in this calculation was the actual raised price of the therapy system in Turkey in the beginning of 2019.

Results: There was an additional 11.953 USD cost for the SSI in 100 amputation patients when standard care was performed. If we apply negative pressure wound therapy (Prevena ${ }^{\mathrm{TM}}$ ) in 25 patients who would be considered as high risk, the additional cost would be 11.361 USD. In the case of median sternotomy, the cost of SSI burden was 27.889 USD for standard care, and the cost burden including negative pressure wound therapy (Prevena ${ }^{\mathrm{TM}}$ ) cost for high-risk patients was calculated as 11.281 USD. In the laparotomy group, the cost burden of SSI in standard care was 165.105 USD, and negative pressure wound therapy (Prevena' ${ }^{\mathrm{TM}}$ ) group had 96.767 USD.

Please cite this article as: Çelikcan G, Kastamoni M, Kahveci R. Cost-Effectiveness of Closed Incison Negative Pressure Wound Therapy for Reducing Surgical Site Infections. Anatol J Family Med 2019;2(3):126-131.

Address for correspondence: Dr. Gaye Çelikcan. Department of Family Medicine, Uludag University, Bursa, Turkey

Phone: +90 5303461929

E-mail: gayeisz81@gmail.com

Received Date: 08.02.2019

Accepted Date: 16.03.2019

Published online: 25.07.2019

(C)opyright 2019 by Anatolian Journal of Family Medicine -

Available online at www.anatoljfm.org

OPEN ACCESS

Conclusion: Applying negative pressure wound therapy (Prevena ${ }^{\mathrm{TM}}$ ) in high-risk patients, as recommended in World Health Organization guideline in different surgery types, demonstrates cost benefit. The cost benefit of PrevenaTM was more apparent in median sternotomy and laparotomy compared to amputation. Negative pressure wound therapy (Prevena ${ }^{\mathrm{T} M}$ ) can be a good choice in high-risk patients in cost perspective. Further studies would be needed to confirm the cost-effectiveness of negative pressure wound therapy (Prevena ${ }^{\mathrm{TM}}$ ) in different types of surgeries.

Keywords: Negative-pressure wound therapy, surgical wound, surgical wound infection

\section{INTRODUCTION}

Surgical site infections (SSI) are among the most common hospital-acquired infections. These type of infections pose substantial healthcare burden since they can increase the morbidity, mortality, and the overall healthcare cost. It is shown that SSI can increase mortality by $3 \%$ and the length of stay by 9.7 days on average. Preventive measures such as prophylactic antibiotic usage, preoperative skin preparation, body washing, and hair removal are still not sufficient. ${ }^{[1]}$

A surgical site complication (SSC) is defined by the Centers for Disease Control and Prevention as "any infection occurring within 30 days post-operatively that can be attributed to surgery, and within one year of placing an implant".[2] SSCs represent a majority of postoperative complications, reaching a prevalence rate of $38 \%$ in surgery departments worldwide. ${ }^{[3]} \mathrm{SSIs}$ and 
related complications following surgical procedures place a significant cost burden to the healthcare system and have been identified as one of the leading causes of hospital-acquired infections. In some countries, these complications are not reimbursed by payers. In the USA, SSI is demonstrated to cause 38.556 USD in medical charges and postoperative dehiscence can add as much as 9.4 extra days, resulting to 40.323 USD additional charges ${ }^{[4]}$ Current standards of care for preventing SSI include preoperative prophylactic systemic antibiotics (for selected surgical procedures), preoperative antiseptic shower/bath, hair removal, aseptic skin preparations, and sterile and meticulous surgical techniques. ${ }^{[5]}$ However, the continued high rates of SSI demonstrate the need for new and innovative measures to prevent these infections.

Recently some risk factors for SSIs have been defined by an international multidiscplinary panel. The panel generated a list of risk factors for the development of SSI based on the evidence-based medicine literature review and panel member experience. The risk factors were grouped under three categories: patient-related risk factors, general incision-related risk factors, and operation-related risk factors. Diabetes mellitus, American Society of Anesthesiologists (ASA) score $>3$, advanced age, obesity, active tobacco use, hypoalbuminemia, corticosteroid usage, active alcoholism, male sex, chronic renal insufficiency, chronic obstructive pulmonary disease, and hematoma are the leading patient-related risk factors. High-tension incision, repeated incisions, extensive undermining, traumatized soft tissue, edema, degree of contamination, emergency procedure, mechanically unfavorable site, prolonged operation time, and postsurgical radiation are the general incision-related risk factors. Open colorectal, open urology, open obstetrics and gynecology (OB/GYN) (obstetrician-gynecologist), incisional hernia repair in general surgery and OB/GYN, postbariatric abdominoplasty, breast reconstruction, big soft tissue defects (necrotizing fasciitis), high-tension incision, soilage risk, repeat incision in plastic/reconstructive surgery, and open reduction and internal fixation of fractures: acetabulum, pilon, calcaneous, tibial, plateau, fasciotomy, above-knee amputation, below-knee amputation in orthopedic surgery, and synthetic graft implantation and sternotomy in cardiovascular surgery are the most common risk factors. ${ }^{[6]}$ Although the list is long, obesity and diabetes mellitus are the two major risk factors studied for a long time in the literature. The obesity prevalence in Turkey is $22 \%$ and diabetes prevalence is $13.7 \%$. ${ }^{[7,8]}$

The World Health Organization (WHO) published a guideline for the prevention of surgical site infection in 2016. ${ }^{[9]}$ In this guideline, negative pressure wound therapy (NPWT) on clean closed incision was recommended as an innovative measure to provide prevention of SSI in high-risk patients when resources are taken into account.

Under the designation closed incision negative pressure therapy (ciNPT), this new technique has shown significant clinical results. Many studies and case reports comparing standard-of-care dressings to ciNPT have reported a decrease in SSIs in a wide spectrum of traumatic, orthopedic, abdominal, sternal, and plastic surgery incisions. The reason for this success may be due to the reported mechanisms of action of the ciNPT, which protects the incision from external wound contamination, strengthens the cohesiveness of the wound edges, removes fluids and infectious materials from the wound, decreases the lateral tension around the incision, and facilitates oxygen saturation, lymphatic flow, and blood microcirculation within the incision area. ${ }^{[10]}$

The purpose of the study is to develop a model to demonstrate the potential cost-effectiveness of using closed incision management system with NPWT (Prevena ${ }^{\mathrm{TM}}$ ) over clean closed surgical incisions in high-risk patients treated with different surgery types.

\section{METHOD}

In this study we developed a model comparing two hypothetic patient cohorts (Group A: standard of care; Group B: negative pressure wound therapy (Prevena ${ }^{\mathrm{TM}}$ )) with 100 patients in each group.The number of surgical site infection patients in different surgery types was calculated according to the local publication showing the incidence of SSI in certain operations. ${ }^{[11]}$ This number of SSI patients was kept in Group A, which hypothetically were treated with standard of care. The number of SSI was assumed to be reduced by applying negative pressure wound therapy (Prevena $^{\mathrm{TM}}$ ) in high-risk patients in Group B. The risk reduction of SSI by negative pressure wound therapy (Prevena ${ }^{\mathrm{TM}}$ ) was determined according to the meta-analysis. We then calculated the cost burden of SSI in different surgery types in USD terms by using local SSI cost data from another local publication. ${ }^{[9]}$

In Group B, $25 \%$ of patients ( 25 patients) were considered to be at high risk and they are patients receiving negative pressure wound therapy (Prevena ${ }^{\mathrm{TM}}$ ). This percentage represented the high-risk obese and diabetic patients undergoing these surgeries. The cost burden of negative pressure wound therapy (Prevena ${ }^{\mathrm{TM}}$ ) for these was added to the SSI cost burden in Group B patients.

The comparison between groups was repeated in three different surgery types, i.e., amputation, laparotomy, and median sternotomy incisions. 


\section{RESULTS}

The prevalence of SSI in amputation is $9.5 \%$ among standart of care patients (Group A); ${ }^{[11]}$ the risk reduction of SSI by ciNPT in this type of surgery is $41(41.0 \%){ }^{[1]}$ Total cost burden of SSI for amputation in group A was found to be 11.953 USD and, the total cost burden of SSI for amputation in group $B$ is 11.361 USD (Table 1).

The prevalence of SSI in median sternotomy is $16(16.0 \%)$ among standart of care patients (Group A); ${ }^{[11]}$ the risk reduction of SSI by ciNPT in this type of surgery is $75(75.0 \%){ }^{[1]}$ Total cost burden of SSI for median sternotomy in group A was found to be 27.889 USD and, the total cost burden of SSI for median sternotomy in group $B$ is 11.281 USD (Table 1).

The prevalence of SSI in laparotomy is $24 \%$ among standart of care patients (Group A); ${ }^{[11]}$ the risk reduction of SSI by ciNPT in this type of surgery is $44 \%{ }^{[1]}$. Total cost burden of SSI for laparotomy in group A was found to be 165.105 USD,

\begin{tabular}{lcc}
\hline $\begin{array}{l}\text { Table 1. The cost of burden comparison between group A and B. } \\
\text { Surgery Type }\end{array}$ & $\begin{array}{c}\text { Group A } \\
\text { (Standart of Care) }\end{array}$ & $\begin{array}{c}\text { Group B } \\
\text { (Prevena }^{\text {TM}} \text { ) }\end{array}$ \\
\hline Amputation & 11.953 USD & 11.361 USD \\
Median Sternotomy & 27.889 USD & 11.281 USD \\
Laparatomy & 165.105 USD & 96.767 USD \\
\hline
\end{tabular}

and the total cost burden of $\mathrm{SSI}$ for laparotomy in group $\mathrm{B}$ is 96.767 USD (Table 1). The details are given in Table 2.

\section{DISCUSSION}

Recent work by the WHO shows that SSI is the most surveyed and frequent type of hospital-acquired infection (HAI) in low- and middle-income countries and it affects up to one-third of patients who have undergone a surgical procedure. ${ }^{[9]}$ Although SSI incidence is lower in high-income countries, it remains the second most frequent type of HAI in Europe and the USA, accounting for $19.6 \%$ of all HAI in Europe in 2011-2012. ${ }^{[12]}$ SSI however is only one component of surgical site occurrences. Postsurgical wound complications, such as SSIs, and surgical site occurrences, such as dehiscence and formation of hematomas or seromas, are a major burden to the patients and the healthcare systems. ${ }^{[13,14]}$

The development of an SSI causes a substantial increase in the clinical and economic burden of surgery. The financial burden of surgery is increased due to the direct costs incurred by prolonged hospitalization of the patients, diagnostic test, and treatment. Certain patients may also require reoperation after the contraction of an SSI, which is associated with considerable additional costs. ${ }^{[15,16]}$ In European hospitals, patients who develop an SSI constitute a financial burden approximately double that of patients who do not develop them. ${ }^{[17]}$

Table 2. The cost of burden comparison between Group A and Group B in 100 patients model

\begin{tabular}{|c|c|c|c|c|c|c|c|}
\hline \multirow[t]{2}{*}{ Surgery Type } & \multicolumn{3}{|c|}{$\begin{array}{c}\text { Group A } \\
\text { (Standart of Care) }\end{array}$} & \multicolumn{3}{|c|}{$\begin{array}{c}\text { Group B } \\
\text { (ciNPT Therapy) }\end{array}$} & \multirow[t]{2}{*}{ Saving w/ciNPT } \\
\hline & Rate & $\begin{array}{l}\text { Additional Cost } \\
\text { per Patient }\end{array}$ & Additional Cost & Rate & $\begin{array}{c}\text { Additional Cost } \\
\text { per Patient }\end{array}$ & Additional Cost & \\
\hline \multicolumn{8}{|l|}{ Laparatomy } \\
\hline Patients w/SSI & $15 \%$ & $\$ 11.007$ & $\$ 165.105$ & $8.40 \%$ & $\$ 11.007$ & $\$ 92.459$ & \\
\hline Patients w/out SSI & $85 \%$ & - & - & $91.60 \%$ & - & - & \\
\hline \multirow[t]{2}{*}{ ciNPT Patients } & $0 \%$ & - & - & $25.00 \%$ & $\$ 172$ & $\$ 4.309$ & \\
\hline & & & $\$ 165.105$ & & & $\$ 96.767$ & $\$ 68.337$ \\
\hline \multicolumn{8}{|l|}{ Median Sternotomy } \\
\hline Patients w/SSI & $5.0 \%$ & $\$ 5.578$ & $\$ 27.889$ & $1.25 \%$ & $\$ 5.578$ & $\$ 6.972$ & \\
\hline Patients w/out SSI & $95.0 \%$ & - & - & $98.75 \%$ & - & - & \\
\hline \multirow[t]{2}{*}{ ciNPT Patients } & $0 \%$ & - & - & $25.00 \%$ & $\$ 172$ & $\$ 4.309$ & \\
\hline & & & $\$ 27.889$ & & & $\$ 11.281$ & $\$ 16.608$ \\
\hline \multicolumn{8}{|l|}{ Amputation } \\
\hline Patients w/SSI & $9.5 \%$ & $\$ 1.258$ & $\$ 11.953$ & $5.61 \%$ & $\$ 1.258$ & $\$ 7.052$ & \\
\hline Patients w/out SSI & $90.5 \%$ & - & - & $94.40 \%$ & - & - & \\
\hline \multirow[t]{2}{*}{ ciNPT Patients } & $0 \%$ & - & - & $25.00 \%$ & $\$ 172$ & $\$ 4.309$ & \\
\hline & & & $\$ 11.953$ & & & $\$ 11.361$ & $\$ 592$ \\
\hline
\end{tabular}


Many factors in the patient's journey through surgery have been identified as contributing to the risk of SSI. Therefore, the prevention of these infections is complex and requires the integration of a range of preventive measures before, during, and after surgery.

We reviewed some SSI burden cost information from different countries. In France, SSI constituted a total per patient medical cost of $€ 17.434$ which is higher than patients without an SSI. ${ }^{[18]}$ In Germany, the total medical cost per patient was significantly elevated in patients who developed an SSI: $€ 36.261$ vs. $€ 13.356 .{ }^{[19]}$ In Italy, in orthopedic and trauma surgery patients, the development of an SSI was associated with additional total medical costs of $€ 32.000$, relative to uninfected patient average cost per SSI of $€ 9.560$. ${ }^{[20]}$ In Spain, the estimated direct total healthcare cost of developing an SSI was $€ 1.084 .639$, which was mainly attributable to prolonged hospitalization (37\%) and other hospital costs (43\%). ${ }^{[21]}$ In the UK, Tanner et al. reported that general surgery patients who contracted an SSI constituted an additional healthcare burden of $£ 10.523$ per patient; the primary cost drivers identified in this study were prolonged LOS and readmission costs. ${ }^{[22]}$

Before moving into Turkish data on the burden of SSI, it would be necessary to review the international data on the burden of SSI in different specialties, particularly in orthopedic surgery, cardiovascular surgery, and general surgery, in order to have a relevant cost-effectiveness analysis.

Studies on orthopedic procedures in the UK have shown that wound complications impose a significant burden on the healthcare system as they increase hospital costs: in hip fractures, the mean total cost per in-patient stay was $£ 15.576$ when an SSI developed versus $£ 6.922$ for noninfected patients. Based on Primary Care Trust tariffs, the mean financial loss per patient with infection was $£ 7.726$, whereas a $£ 153$ cost saving was gained per patient without infection. ${ }^{[23]}$ The mean cost of revision knee arthroplasty with infection was more than threefold higher versus noninfection ( $£ 30.011$ vs. 9.655 , respectively). ${ }^{[24]}$ They also prolong hospital stay: the mean length of stay for patients with revision knee arthroplasty with infection was more than twofold versus aseptic revision. ${ }^{[24]}$ After surgery for proximal femoral fracture, patients with deep wound infection had a substantially increased hospital stay versus patients without infection (48 vs. 13 days, respectively). ${ }^{[25]}$ This increased readmission rates: infection was the most common (31.0\%) reason for readmission after hip fracture surgery in elderly patients. ${ }^{[26]}$

In the UK, the Nosocomial Infection National Surveillance Service also showed that SSIs in cardiothoracic/vascular surgery impose a significant burden on the healthcare system. ${ }^{[27]}$

In Turkey, the health economics data is limited. The burden of SSI in different specialties and in certain surgical procedures is studied and published. ${ }^{[28]}$ Having this data provided an opportunity for our study. In general surgery, laparotomy surgery patients would stay 10 days in hospital on average, when there is an SSI, and the length of hospital stay may increase up to 38 days which brings an additional burden of 775 USD per patient. In cardiac surgery the additional cost burden of SSI would be 5578 USD. In orthopedic surgery and in major amputation, the patients stay 10 days on average, and in case of SSI this length of stay is extended up to 30 days which brings an additional cost of 1258 USD.

This economic burden is underestimated and yet no measure to prevent SSI is sufficient. NPWT applied on clean closed incision is a recent innovative technique that is proven to be effective in preventing SSI in different settings. There are two high-quality meta-analyses which demonstrate that negative pressure therapy would reduce $\mathrm{SSI}$, dehiscence, and hematoma formation in different surgical types. ${ }^{[1,29]}$ The WHO recommended NPWT in prophylactic usage in high-risk patients taking into consideration these meta-data. The vast majority of this data comes from the studies of negative pressure wound therapy (Preve$\mathrm{na}^{\mathrm{TM}}$ ) compared to the standard of care. negative pressure wound therapy (Prevena ${ }^{\mathrm{TM}}$ ) is the only commercial negative pressure therapy device available in Turkey built for prophylactic use in closed incisions.

The evidence supports the hypothesis that reduction of lateral tension and hematoma or seroma and an acceleration of the elimination of tissue edema are the main mechanisms of action of incisional NPWT. Together these mechanisms are able to improve the speed, strength, and quality of incisional wound healing, thus minimizing the failures of healing that lead to infection and/or dehiscence. It remains possible that some redistribution of blood flow around closed incisions could supplement these mechanisms. ${ }^{[30]}$

There have been several studies that investigated the costeffectiveness of negative pressure wound therapy (Preve$\left.n a^{T M}\right) .{ }^{[1-35]}$ However it is clear that its cost-effectiveness is time-dependent and country-spesific. To our knowledge, our cost-effectiveness analysis is the first study that examined the cost-effectiveness of commercial closed incision negative pressure device in reducing SSIs in Turkey and most probably the first international analysis investigating these three particular surgery types (laparotomy, amputation, and sternotomy).

In our analysis we found that there was an additional 11.953 
USD cost for the SSI in 100 amputation patients when standard care was performed. If we apply negative pressure wound therapy (Prevena ${ }^{\mathrm{TM}}$ ) in 25 patients who would be considered as high risk and calculate the total cost burden, the additional cost would be 11.361 USD. The total cost burden was calculated as the cost of reduced SSI plus the cost of negative pressure wound therapy (Prevena' ${ }^{\mathrm{TM}}$ ) for 25 patients. In the second model, if we take 100 patients who have undergone median sternotomy, the cost of SSI burden will be 27.889 USD for standard care and the total SSI burden including negative pressure wound therapy (Preve$\mathrm{na}^{\mathrm{TM}}$ ) cost for high-risk patients is calculated as 11.281 USD. The third group of patients were laparotomy patients. In this model, the cost burden of SSI in standard care was 165.105 USD, whereas the negative pressure wound therapy (Preve$\mathrm{na}^{\mathrm{TM}}$ ) group had 96.767 USD of cost burden in total.

There are some limitations of our study. Due to the hypothetical design of the study, the lack of knowledge of the characteristics of the groups; the inability to make the exact operational definitions and the fact that the costs other than the operation and related factors affecting cost effectiveness are not known and therefore cannot be reflected are the most important limitations of the study. Moreover data in terms of cost of complications of different surgeries in Turkey is limited. So we had to project the cost of complications to today. In order to keep consistency we used USD as cost data. This study has been performed in desktop settings, in a cost model, so the findings of the study has to be interpreted with caution. A real life study that would be on clinical settings would be a valuable contribution to the literature.

\section{CONCLUSION}

Applying PrevenaTM in high-risk patients, as recommended in the WHO guideline in different surgery types demonstrates cost benefit in amputation, laparotomy, and median sternotomy. The cost benefit of negative pressure wound therapy (Prevena ${ }^{\mathrm{TM}}$ ) was more apparent in median sternotomy and laparotomy compared to amputation. negative pressure wound therapy (Prevena ${ }^{\mathrm{T} M}$ ) can be a good choice in high-risk patients to prevent SSIs in cost perspective. Reduced morbidity and mortality rates are other important benefits of applying NPWT in closed incision management. Further studies would be needed to confirm the cost-effectiveness of negative pressure wound therapy (Prevena ${ }^{\mathrm{TM}}$ ) in different types of surgeries.

\section{Disclosures}

Ethics Committee Approval: This study uses information freely available in the public domain and the analysis of datasets in open source hence, according to The National Code of Clinical
Trials and the declaration of Helsinki this study does not need an approval for local Ethics Committee.

Peer-review: Externally peer-reviewed.

Conflict of Interest: None declared.

Authorship Contributions: Concept - R.K., M.K., G.Ç.; Design M.K., G.Ç., R.K.; Supervision - R.K.; Materials - G.Ç., R.K.; Data collection \&/or processing - M.K., G.Ç.; Analysis and/or interpretation - R.K., M.K., G.Ç.; Literature search - R.K., M.K.; Writing - M.K.; Critical review - M.K.

\section{REFERENCES}

1. Semsarzadeh NN, Tadisina KK, Maddox J, Chopra K, Singh DP. Closed Incision Negative-Pressure Therapy Is Associated with Decreased Surgical-Site Infections: A Meta-Analysis. Plast Reconstr Surg 2015;136(3):592-602. [CrossRef]

2. Stevens DL. Treatments for skin and soft-tissue and surgical site infections due to MDR Gram-positive bacteria. J Infect 2009;59 Suppl 1:S32-S39. [CrossRef]

3. Nichols RL. Preventing surgical site infections: a surgeon's perspective. Emerg Infect Dis 2001;7(2):220-224. [CrossRef]

4. Mullins A, Paulos M. Cost effectiveness model: comparison of closed incision management using negative pressure and standard of care over clean closed incisions based on a 2012 randomized controlled trial. Value in Health 15 (2012) A68.

5. Stevens DL, Bisno AL, Chambers HF, Dellinger EP, Goldstein EJ, Gorbach SL, Hirschmann JV, Kaplan SL, Montoya JG, Wade $J C$. Practice guidelines for the diagnosis and management of skin and soft tissue infections: 2014 update by the Infectious Diseases Society of America. Clin Infect Dis 2014;59(2):e10-52.

6. Willy C, Agarwal A, Andersen CA, Santis G, Gabriel A, Grauhan O, Guerra OM, Lipsky BA, Malas MB, Mathiesen LL, Singh DP, Reddy VS. Closed incision negative pressure therapy: international multidisciplinary consensus recommendations. Int Wound J 2017;14(2):385-398. [CrossRef]

7. Yumuk VD. Prevalence of obesity in Turkey. 2005 (https://doi. org/10.1111/j.1467-789X.2005.00172.x) [CrossRef]

8. Satman İ, İmamoğlu Ş, Yılmaz C, Ayvaz G, Çömlekçi A. Türkiye'de ve Dünya'da Diyabet-Türkiye Endokrinoloji ve Metabolizma Derneği (TEMD) Diabetes Mellitus Çalışma ve Eğitim Grubu Raporu. Journal of the Society of Endocrinology and Metabolism of Turkey 2012;16 Suppl 1 (http://www.turkjem.org/uploads/pdf/16-1-1_Diyabet_Raporu.pdf)

9. Global Guidelines for the Prevention of Surgical Site Infection, 2016. (https://www.who.int/gpsc/ssi-guidelines/en/ , January 2019)

10. Pleger SP, Nink N, Elzien M, Kunold A, Koshty A, Böning A. Reduction of groin wound complications in vascular surgery patients using closed incision negative pressure therapy (ciNPT): a prospective, randomised, single-institution study. Int Wound J 2018;15(1):75-83. [CrossRef]

11. Leblebicioglu H, Erben N, Rosenthal VD, Sener A, Uzun C, Senol G, Ersoz G, et al. Surgical site infection rates in 16 cities in Turkey: findings of the International Nosocomial Infection Control Consortium (INICC). Am J Infect Control 2015;43(1):48-52. [CrossRef] 
12. European Centre for Disease Prevention and Control. Point prevalence survey of healthcare associated infections and antimicrobial use in European acute care hospitals. 2011-2012 (http://ecdc.europa.eu/en/publications/Publi cations/healthcare-associated-infections-antimicrobial-use-PPS. pdf) [last accessed July 2016].

13. Hyldig N, Birke-Sorensen $H$, Kruse M, Vinter C, Joergensen JS, Sorensen JA, Mogensen O, Lamont RF, Bille C. Meta-analysis of negative-pressure wound therapy for closed surgical incisions. Br J Surg 2016;103(5):477-486. [CrossRef]

14. Scalise A, Calamita R, Tartaglione C, Pierangeli M, Bolletta E, Gioacchini M, Gesuita R, Di Benedetto G. Improving wound healing and preventing surgical site complications of closed surgical incisions: a possible role of Incisional Negative Pressure Wound Therapy. A systematic review of the literature. Int Wound J 2016;13(6):1260-1281. [CrossRef]

15. Badia JM, Casey AL, Petrosillo N, Hudson PM, Mitchell SA, Crosby C. Impact of surgical site infection on healthcare costs and patient outcomes: a systematic review in six European countries. J Hosp Infect 2017;96(1):1-15. [CrossRef]

16. O'Keeffe $A B$, Lawrence $T$, Bojanic S. Oxford craniotomy infections database: a cost analysis of craniotomy infection. $\mathrm{Br} J$ Neurosurg 2012;26(2):265-269. [CrossRef]

17. Broex EC, van Asselt AD, Bruggeman CA, van Tiel FH. Surgical site infections: how high are the costs? J Hosp Infect 2009;72:193-201. [CrossRef]

18. Penel N, Lefebvre JL, Cazin JL, Clisant S, Neu JC, Dervaux B, Yazdanpanah Y. Additional direct medical costs associated with nosocomial infections after head and neck cancer surgery: a hospital-perspective analysis. Int J Oral Maxillofac Surg 2008;37(2):135-139. [CrossRef]

19. Graf K, Ott E, Vonberg RP, Kuehn C, Schilling T, Haverich A, Chaberny IF. Surgical site infections--economic consequences for the health care system. Langenbecks Arch Surg 2011;396(4):453-459. [CrossRef]

20. Nobile M, Navone P, Orzella A, Colciago R, Auxilia F, Calori G. Developing a model for analysis the extra costs associated with surgical site infection (SSIs): an orthopaedic and traumatological study run by the Gaetano Pini Orthopaedic Institute. Antimicrob Resist Infect Control 2015;4 Suppl 1:P68. [CrossRef]

21. Alfonsa JL, Pereperez SB, Canoves JM, Martinez MM, Martinez IM, Martin-Moreno JM. Are we really seeing the total costs of surgical site infection? A Spanish study. Wound Repair Regen 2007;15:474-481. [CrossRef]

22. Jenks PJ, Laurent M, McQuarry S, Watkins R. Clinical and economic burden of surgical site infection (SSI) and predicted financial consequences of elimination of SSI from an English hospital. J Hosp Infect 2014;86(1):24-33. [CrossRef]

23. Wijeratna MD, McRoberts J, Porteous MJ. Cost of infection af- ter surgery for intracapsular fracture of the femoral neck. Ann R Coll Surg Engl 2015;97(4):283-286. [CrossRef]

24. Kallala RF, Vanhegan IS, Ibrahim MS, Sarmah S, Haddad FS. Financial analysis of revision knee surgery based on NHS tariffs and hospital costs: does it pay to provide a revision service? Bone Joint J 2015;97-B(2):197-201. [CrossRef]

25. Pollard TC, Newman JE, Barlow NJ, Price JD, Willett KM. Deep wound infection after proximal femoral fracture: consequences and costs. J Hosp Infect 2006;63(2):133-139. [CrossRef]

26. Hahnel J, Burdekin H, Anand S. Re-admissions following hip fracture surgery. Ann R Coll Surg Engl 2009;91(7):591-595.

27. Coello R, Charlett A, Wilson J, Ward V, Pearson A, Borriello P. Adverse impact of surgical site infections in English hospitals. J Hosp Infect 2005;60(2):93-103. [CrossRef]

28. Çiftçi IH, Şahin DA, Kır Şahin F, Çetinkaya Z, Şafak B, Dilek ON. Cerrahi Alan Enfeksiyonlarında Etiyoloji ve Maliyete Etkisi. The Medical Journal of Kocatepe 2005; 6:17-22.

29. De Vries FE, Wallert ED, Solomkin JS, Allegranzi B, Egger $M$, Dellinger EP, Boermeester MA. A systematic review and meta-analysis including GRADE qualification of the risk of surgical site infections after prophylactic negative pressure wound therapy compared with conventional dressings in clean and contaminated surgery. Medicine (Baltimore) 2016;95(36):e4673. [CrossRef]

30. Karlakki S, Brem M, Giannini S, Khanduja V, Stannard J, Martin R. Negative pressure wound therapy for managementof the surgical incision in orthopaedic surgery: A review of evidence and mechanisms for an emerging indication. Bone Joint Res 2013;2(12):276-284. [CrossRef]

31. Matatov T, Reddy KN, Doucet LD, Zhao CX, Zhang WW. Experience with a new negative pressure incision management system in prevention of groin wound infection in vascular surgery patients. J Vasc Surg 2013;57(3):791-795. [CrossRef]

32. Grauhan O, Navasardyan A, Hofmann M, Müller P, Stein J, Hetzer R. Prevention of poststernotomy wound infections in obese patients by negative pressure wound therapy. J Thorac Cardiovasc Surg 2013;145(5):1387-1392. [CrossRef]

33. Lewis LS, Convery PA, Bolac CS, Valea FA, Lowery WJ, Havrilesky LJ. Cost of care using prophylactic negative pressure wound vacuum on closed laparotomy incisions. Gynecol Oncol 2014;132(3):684-689. [CrossRef]

34. Tuffaha HW, Gillespie BM, Chaboyer W, Gordon LG, Scuffham PA. Cost-utility analysis of negative pressure wound therapy in high-risk cesarean section wounds. J Surg Res 2015;195(2):612-622. [CrossRef]

35. Chopra K, Gowda AU, Morrow C, Holton L 3rd, Singh DP. The Economic Impact of Closed-Incision Negative-Pressure Therapy in High-Risk Abdominal Incisions: A Cost-Utility Analysis. Plast Reconstr Surg 2016;137(4):1284-1289. [CrossRef] 